\title{
Smart Garbage Collection
}

\author{
Tejas Kamble ${ }^{1}$, Vishal More ${ }^{2}$, Aishwarya Jathar ${ }^{3}$, Dhananjay Gurav ${ }^{4}$, Prof.L.J.Deokate ${ }^{5}$ \\ Student, IT Dept, Sinhgad Academy of Engineering, Pune, India ${ }^{123,4}$ \\ Guide, IT Dept, Sinhgad academy of Engineering, Pune, India ${ }^{5}$
}

\begin{abstract}
India is a developing country with a huge population. This ever increasing population degrades the cleanliness of sustainable environment. To maintain splendor, the Indian Government launched the campaign of "Swachh Bharat" mission popularly known as clean India movement for making an India clean. The campaign objective is to make city smart by reducing or eliminating open defecation through construction of individual, cluster and community toilets. Smart city is a future reality in India, the concept of smart city has several definitions but still no universal definition is accepted. Finding the garbage bins whether it is filled or not is very difficult. The idea is simple and is driven by the fact that garbage containers require very frequent cleaning, which is not always possible. This leads to unhealthy environment.. For that we introduce our system to solve this problem.
\end{abstract}

Keywords: GSM, GPS, Application smart phone

\section{INTRODUCTION}

In Nowadays certain actions are taken to improve the level of cleanliness in the country. People are getting more active in doing all the things possible to clean their surroundings. Various movements are also started by the government to increase cleanliness. We will try to build a system which will notify the corporations to empty the bin on time. In this system, we will put a sensor on top of the garbage bin which will detect the total level of garbage inside it according to the total size of the bin. When the garbage will reach the maximum level, a notification will be sent to the corporation's office, then the employees can take further actions to empty the bin. This system will help in cleaning the city in a better way. By using this system people do not have to check all the systems manually but they will get a notification when the bin will get filled.

The main objectives of our this system is 1. Monitoring the waste management. 2. Providing a smart technology for waste system. 4. Reducing human time and effort 5. Resulting in healthy and waste ridden. On this manner, proper authority could be conscious and people could get relief.

\section{LITERATURE SURVEY}

Monika K A, Rao N, Prapulla S B and Shobha G 2016 Smart Garbage container-An Efficient Garbage Monitoring System International Journal of Engineering Science and Computing 6 7113-16[1]

A Smart Garbage container proposed by [1], based on IoT in which the smart bin was built on a platform which was based on Aurdino Uno board which was interfaced with a GSM modem and an ultrasonic sensor. The sensor was placed on the top of the bin. A threshold level was set as $10 \mathrm{~cm}$. As the garbage reaches the level of threshold, the sensor triggers the GSM modem which alerts the associated authority till the garbage in the bin is emptied. At the end a conclusion was made thatvarious issues like affordability, maintenance and durability were addressed when these smart bins were designed. It also contributed towards a hygienic and clean environment in the process of building a smart city.

“Efficient waste collection system",Saurabh Dugdhe ; Pooja Shelar ; Sajuli Jire ; Anuja Apte 2016 International Conference on Internet of Things and Applications (IOTA)[2]

Waste is an important issue, which needs to be tackled smartly. Wisely, we segregate the waste at our homes for ease at processing and recycling. We observed trash vans/trucks come irregular to homes creating a havoc of households. Due to this many civilians empty their overloaded garbage containers in open spaces. This in turn increases environmental pollution. We got inspired from "Swachh Bharat Abhiyan" which is a national campaign by the Government of India, to clean the streets, roads and infrastructure of the country. The citizens want to have better service, lower cost and having easy accessible reports on what has been done and how much it cost. The proposed system aims to schedule trucks by finding shortest path between the almost filled waste bins and bins which have produced harmful gases and gives a route for collection. The system will consist of setting up smart waste bins/ trash cans per society, which will be IoT enabled. These smart bins will transmit information about its fill status and harmful gas levels. Proposed system 
provides efficient and optimized routes to collect maximum waste with less cost and fuel. The system provides estimated dates for collection of waste, real time bin status, expected fill up dates for the bins, and optimized shortest path for waste collection

M. Faccio, A. Persona, and G. Zanin: Waste collection multi objective model with real time traceability data [3] Modern traceability devices, like volumetric sensors, identification RFID (Radio Frequency Identification) systems, GPRS (General Packet Radio Service) and GPS (Global Positioning System) technology, permit to obtain data in real time, which is fundamental to implement an efficient and innovative waste collection routing model.

\section{EXISTING SYSTEM}

The existing system has the limitations as time consuming, trucks go and empty the containers, even they are empty. The cost is high with unhygienic environment. Even the bad odour causes the unhealthy environment. So, proposed model talks about how to make use of the recent advancements in technology to make our place clean and tidy. Hazardous rubbish like empty petrol cans can cause fires igniting other trash when the truck compactor is operating. Bins may be locked or stored in secure areas to avoid having non-paying parties placing rubbish in the bin. The cost of old waste is also a concern in collection of waste across the globe.

\section{Drawbacks of Existing System}

1. In the present days we have many more android applications for smart city development which is not much

2. effective

3. Government campaigned too many times to see the clean city by the name called "swachha bharat" which is fading away.

4. There is no record to show that our municipal corporation is working properly or not.

5. Government is not taking any actions towards Municipal Corporation.

6. There are no such rewards for volunteers when they work for our city to see the clean city.

\section{PROPOSE SYSTEM}

The proposed system is android application and it is developed to automate the detection of garbage container level and garbage container location. In this system Contractor and PMC has login page to connect with system. The contractor get notification regarding garbage container through various sensor used in system on android application. As soon as sms is received contractor/PMC send volunteer for cleaning garbage container ,Live tracking system is used to track the location of garbage container. Odour sensor is used for detection of odour and Load sensor is used to check level of garbage container. After the container is clean by volunteer sms is send to contractor/PMC. Level sensor notifies about garbage level in garbage container. Contractor /PMC can also check the status of garbage container.

\section{SYSTEM ARCHITECTURE}

Following diagram is our system's architecture diagram:-

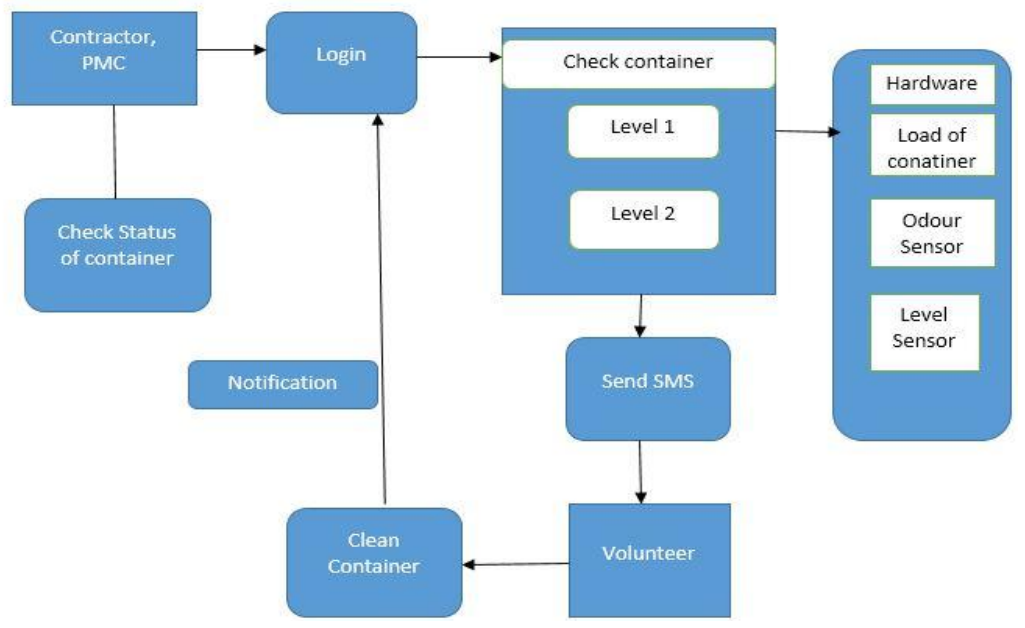

Figure 1: system architecture 
In this system Architecture the main modules are:-.

1. Contractor and PMC:-Receive the sms through the system about garbage container using sensor and send notification to volunteer for cleaning container.

2. Admin:- Save the information of the user

3. It will send the data through the GSM.

4. Using GPS it will show the location of Container. Live tracking is use in this system.

5. Using database it will send the SMS to contactor to clean the container.

\section{METHODOLOGIES}

In that shortest path algorithm is used to detect the nearby Container. And using GPS and GSM module can detect the level of container. User can see all of the nearby garbage container in map we come across the closest garbage container the use of shortest set of rules.

\section{ALGORITHM}

1) Create a set sptSet (shortest path tree set) that keeps track of vertices included in shortest path tree, i.e., whose minimum distance from source is calculated and finalized. Initially, this set is empty. In this step we track the container and the position of container.

2) Assign a distance value to all vertices in the input graph. Initialize all distance values as INFINITE. Assign distance value as 0 for the source vertex so that it is picked first. Finding the distance of location and the garbage container.

3) It detect the container identify the level using level sensor and odour sensor.

\section{MODULES}

Contractor: For a Android application Contractor can register the application. Then Registration is successful then login the application. And send the SMS to the PMC and supervisor.

PMC and supervisor: Register the application. And registration is successful then login the application.

GPS: Using GPS they can find the location of container. Live tracking is done.

GSM module: They can track the Container .and check the level of container.

Sensors: Load sensor and odour sensor is used to check the load of fill container and sensing bad odour .

Database: It will save the information of container. And send the information to the user.

\section{MATHEMATICAL MODEL}

In $\mathrm{S}=\{\mathrm{U}, \mathrm{C}, \mathrm{D}, \mathrm{Mgs}, \mathrm{V}\}$

Server $=\{$ IP, MAC $\}$

Identify the inputs I.

$\mathrm{I}=\{\mathrm{U}, \mathrm{V}, \mathrm{C}\}$

Where,

$\mathrm{U}$ is a set of users

u1, u2, u3.......un $€ \mathrm{U}$

There can be number of users in our system which interacts with our developed system and uses features of our system.

$\mathrm{C}$ is Municipal Corporation

$\mathrm{V}$ is volunteer

$\mathrm{D}$ is set of Devices

$\mathrm{d} 1, \mathrm{~d} 2, \ldots . . \mathrm{dn} € \mathrm{D}$

IP is an IP address of Server (S)

MAC is MAC address of Server (S)

Identify set of Function. Let $\mathrm{F}$ be the set of Functions.

$\mathrm{F}=\{\mathrm{F} 1, \mathrm{~F} 2, \mathrm{~F} 3\}$

Where,

$\mathrm{F} 1$ = Convey message to PMC

F2 = Contractor will inform to labours

on.

$\mathrm{F} 3$ = check workdone

Identify the Outputs. Let $\mathrm{O}$ be the set of outputs.

$\mathrm{O}=\{\mathrm{Msg}\}$

Where,

$\mathrm{O} 1$ = Information to users 
$\mathrm{O} 2$ = Successfully clean dustbin

Final State:

FS = Successfully utilized Application

Failure case: $\mathrm{Fl}=$ Errors in input parameters

\section{CONCLUSION}

The main objective is to maintain the level of cleanliness in the city and form an environment which is better for living. By using this system we can constantly check the level of the garbage in the garbage containers which are placed in various parts of the city. If particular garbage container has reached the maximum level then the employees can be informed and they can immediately take certain actions to empty it as soon as possible. The employees can check the status of these bins anytime on their mobile phones. This can prove to be a very useful system if used properly. The system can be used as a benchmark by the people who are willing to take one step further for increasing the cleanliness in their respected areas.

The waste accumulated in the bin directly affects the environment and also affects the people's health. To overcome this problem, this paper provides a practical solution to help the city waste management system. This paper has described the development of a smart garbage monitoring system, which is based on Android app.

\section{REFERRENCES}

[1]. Monika K A, Rao N, Prapulla S B and Shobha G 2016 Smart Garbage container-An Efficient Garbage Monitoring System International Journal of Engineering Science and Computing 6 7113-16

[2]. Efficient waste collection system",Saurabh Dugdhe ; Pooja Shelar ; Sajuli Jire ; Anuja Apte 2016 International Conference on Internet of Things and Applications (IOTA)

[3]. M. Faccio, A. Persona, and G. Zanin: Waste collection multi objective model with real time traceability data

[4]. [4] C. K.M. Lee, T. Wu, International Conference on Industrial Engineering and Engineering Management, 798 (2014) A.F. Thompson, A.H. Afolayan, E.O. Ibidunmoye, Information Science, Computing and Telecommunications, 206 (2013)

[5]. Demers, M.N., "Fundamentals of geographic information systems," Wiley, March 2009.

[6]. M. A. Al Mamun, M. A. Hannan, A. Hussain, and H. Basri, "Wireless Sensor Network Prototype for Solid Waste Bin Monitoring with Energy Efficient Sensing Algorithm," in 2013 IEEE 16th International Conference on Computational Science and Engineering, 2013 , pp. $382-387$.

[7]. O. M. Johansson, "The effect of dynamic scheduling and routing in a solid waste management system," Waste Manag., vol. 26, no. 8, pp. 875$885,2006$.

[8]. F. Vicentini, A. Giusti, A. Rovetta, X. Fan, Q. He, M. Zhu, and B. Liu, "Sensorized waste collection container for content estimation and collection optimization," Waste Manag., vol. 29, no. 5, pp. 1467-1472, 2009.

[9]. M. A. Hannan, M. Arebey, R. A. Begum, and H. Basri, "An automated solid waste bin level detection system using a gray level aura matrix," Waste Manag., vol. 32, no. 12, pp. 2229-2238, 2012

[10]. Detection of Diabetic Retinopathy in Retinal Images Using MLP Classifier", Amol Prataprao Bhatkar ; G.U. Kharat, 2015 IEEE International Symposium on Nanoelectronic and Information Systems

[11]. Bode B, Gross K, Rikalo N, Schwartz S, Wahl T, Page C, Gross T, Mastrototaro J: Alarms based on real-time sensor glucose values alert patients to hypo- and hyperglycemia: the Guardian continuous monitoring system. Diabetes Technol Ther 2004;6:105-113.

[12]. Dr Saravanakumar, Eswari, Sampath, Lavanya "Predictive Methodology for Diabetic Data Analysis in Big Data," ELSEVIER, ISBCC 2015.

[13]. Dharwadkar,"Weblog Analysis Using Hadoop," National Research Symposium on Computing - RSC 2016, ISBN: 978-81-931456-1-8, Dec. $19-20,2016$

[14]. Lu Y, Gribok AV, Ward WK, Reifman J: The importance of different frequency bands in predicting subcutaneous glucose concentration in type 1 diabetic patients. IEEE Trans Biomed Eng2010;57:1837-1844.

[15]. E. Daskalaki, K. Norgaard, Zuger T., A. Prountzou, P. Diem, S. Mougiakakou, “An Early Warning System for HypoglycemicHyperglycemic Events Based on Fusion of Adaptive Prediction Models", Journal of Diabetes Science and Technology, vol. 7(3), pp. 689-698, 2013. 